\title{
EL PRINCIPIO DE NEUTRALIDAD EN INTERNET. UNA APORTACIÓN A LA LIBERTAD DE COMUNICACIÓN EN INTERNET DESDE EL PENSAMIENTO DE FRANCISCO DE VITORIA*
}

\section{The net neutrality principle on the internet. A contribution to the freedom of communication on the internet from the thought of Francisco de Vitoria}

\author{
José J. Albert Márquez \\ Universidad de Córdoba (España) \\ ji1almaj@uco.es
}

http://dx.doi.org/10.18543/ed-66(2)-2018pp71-103

Recibido: 30.10 .2018

Aceptado: 21.11.2018

\section{Resumen}

La relevancia que hoy día tiene internet para recibir y emitir mensajes hace que cualquier limitación a un régimen que nació bajo el parámetro de la libertad sea vista con preocupación. En la actualidad, se cuestiona que toda la información que transita por la red deba hacerlo a la misma velocidad, y que sean las empresas que realizan el servicio de transporte o los propios gobiernos quienes decidan en qué términos se

* Cómo citar / Citation 'Chicago-Deusto' (Autor-fecha / Author-date / Lista de referencias / Reference list entries): Albert Márquez, José J. 2018. «El principio de neutralidad en internet. una aportación a la libertad de comunicación en internet desde el pensamiento de Francisco de Vitoria». Estudios de Deusto 66, n. ${ }^{\circ} 2:$ 71-103. http://dx.doi.org/10.18543/ ed-66(2)-2018pp71-103.

Proyecto de Investigación «Administración pública y derechos fundamentales: nuevas perspectivas", DER2015-67695-C2-2-P (MINECO/FEDER). 
limita el acceso a internet. En el S. XVI, Francisco de Vitoria argumentaba que existe entre todas las personas un derecho natural a la comunicación en sociedad, principio que hoy día constituiría un serio argumento en favor de la libertad en la red y de la neutralidad de empresas y gobiernos en este punto.

\title{
Palabras clave
}

Neutralidad en la red; Ius communicationis; Bienes comunes.

\begin{abstract}
The relevance that the Internet has today to receive and issue messages makes that any limitation to a regime that was born under the parameter of freedom be seen with concern. At present, it is questioned that all the information that transits through the network must do so at the same speed, and that it is the companies that carry out the transport service or the governments themselves who decide in what terms access to the Internet is limited. In the sixteenth century, Francisco de Vitoria argued that there is a natural right among all people to communication in society, a principle that today would be a serious argument in favor of freedom in the network and the neutrality of companies and governments in this point.
\end{abstract}

\section{Keywords}

Net neutrality; Ius communicationis; Commons. 


\begin{abstract}
SUMARIO: I. INTRODUCCIÓN. II. LA DENOMINADA «NEUTRALIDAD EN LA RED». 1. Concepto y planteamiento del problema. 2. Ataques al principio de neutralidad. La gestión del tráfico en internet. III. LOS PRINCIPIOS INSPIRADORES DE LAS SOLUCIONES NORMATIVAS SOBRE LA NEUTRALIDAD EN LA RED. 1. Estados Unidos: de la aparente neutralidad a un futuro incierto. 2. Unión Europea: el principio general de «neutralidad tecnológica». IV. UN POSIBLE ARGUMENTO EN FAVOR DE LA LIBERTAD DE COMUNICACIÓN EN LA RED: EL «IUS COMMUNICATIONIS» DE Francisco de Vitoria. V. Conclusión. Bibliografía. Recursos ELECTRÓNICOS.
\end{abstract}

\title{
«...comunitatem esse naturalissimam communicationem naturae convienentissimam» ${ }^{1}$ \\ Francisco de Vitoria, De potestate civili, 4
}

\section{INTRODUCCIÓN}

Cuando en los Estados Unidos de Norteamérica a finales de la década de los cincuenta del pasado siglo se ponía en marcha un programa militar destinado a mejorar la tecnología para intentar frenar los avances tecnológicos soviéticos en el marco de la carrera espacial, era sencillamente insospechable el alcance mundial de dicha iniciativa. El proyecto ARPA (Agencia de Proyectos de Investigación Avanzados) logró comunicar entre sí varias computadoras, a las que luego se fueron sumando más y más ordenadores, comenzándose así a configurar la inmensa red que hoy día llamamos genéricamente «internet»².

No obstante, hubo que esperar unas tres décadas para que se creara la «red mundial», es decir, la «Word Wide Web», o «www», gracias fundamentalmente al trabajo de un equipo de científicos capitaneado por el ingeniero de computación británico Timothy («Tim») Berners-Lee, a quien se tiene como «padre» de la red. A Berners-Lee y su equipo les cupo el mérito de crear la red tal y como la entendemos hoy día, gracias al desarrollo de la estructura «Www», comenzando a principios de la década de los noventa por la implementación del protocolo - por sus siglas en inglés- http (hypertext transfer

1 «La sociedad es como si dijéramos una natural comunicación, muy conveniente a la naturaleza», Vitoria, Francisco de, De Potestate Civile, de la Potestad Civil, en Obras de Francisco Vitoria, Relecciones Teológicas, edición de Teófilo Urdanoz, O.P., (Madrid: Biblioteca de Autores Cristianos, 1960), 156.

2 Vid., Andrew Puddephatt, «Internet y la libertad de expresión», Cuadernos de Discusión de comunicación Información, $\mathrm{n}^{\mathrm{o}} 6$ disponible en http://unesdoc.unesco.org/ images/0024/002466/246670S.pdf UNESCO, 2016, último acceso 14 abril 2018. 
protocol) que permite a las máquinas reconocerse y comunicarse mutuamente (comprende la «sintaxis» y la «semántica» de su lenguaje). Luego se creó el lenguaje HTML (o HyperText Markup Languaje) o lenguaje de etiquetas de hipertexto para la creación de páginas web, y después el sistema de localización de objetos en la red URL (Uniform Resurce Locator) que funciona como una cadena de caracteres que permite asignar una dirección única a cada recurso de internet.

Solo con posterioridad a estos desarrollos básicos se produjo el crecimiento exponencial del fenómeno internet, pues dieron pie al desarrollo de navegadores que sobre la base del protocolo «http» popularizaron definitivamente la red. Simplificando mucho, podríamos decir que, a través de la web, y gracias a ciertos protocolos (reglas de lenguaje homogeneizadas), podemos navegar por un nuevo mundo virtual. Como hemos señalado en otra sede «la herramienta "internet", instalada en cualquier dispositivo al efecto (ordenadores personales, teléfonos, tabletas, navegadores, e incluso relojes de última generación) supone una ventana al mundo, a través de la cual tenemos la posibilidad de ver y de ser vistos $»^{3}$. En suma, coincidimos con Diego Medina cuando escribe, con relación al fenómeno internet, que «puede afirmarse, sin temor a duda, que el hombre, como concepto, nace unido al desarrollo de herramientas y a la capacidad de diseñarlas y usarlas. La técnica, entendida como destreza en el manejo de instrumentos, es uno de los primeros saberes razonados que comienza a desarrollar el ser humano» ${ }^{4}$.

En la práctica, para el usuario común, internet funciona como una inmensa autopista por la que circulan todo tipo de contenidos (información, datos, música, videos, etc.) pero que en sí misma es neutral. Esto es: por definición la red (o las diversas entidades que controlan su funcionamiento) no entra en los contenidos de lo que transporta, del mismo modo que el mar en sí mismo tampoco discrimina entre los distintos tipos de embarcaciones que lo surcan a diario. No se imponen distintas velocidades de navegación en consideración a lo que, en su caso, se pueda pagar de peaje, ni en atención a lo que se transporte en cada caso. Los paquetes de información se entregan y reciben en la red por riguroso orden de llegada o salida, aunque en ocasiones se producen problemas de gestión del tráfico.

En todo caso, resulta fundamental recordar el carácter puramente instrumental de internet. La red de redes no constituye un fin en sí misma, pero

3 José J. Albert Márquez, «Algunas reflexiones sobre el derecho a la intimidad en la red. Especial referencia al llamado «derecho al olvido»». En Cambios Tecnológicos y Derecho, ed., por Diego Medina Morales (Córdoba: El Granado Ediciones Digitales, 2015) 19-45, cita a la p. 38.

${ }^{4}$ Diego Medina Morales, introducción a Cambios Tecnológicos y Derecho, (Córdoba: El Granado Ediciones Digitales, 2015), VII. 
configura un mundo paralelo, con leyes o normas paralelas que traspasan las clásicas categorías de estado-nación, soberanía, o democracia; así lo señaló a finales del siglo pasado Lawrence Lessig, profesor de Derecho de Harvard, cuando sostenía que el código de software y los estándares tecnológicos constituyen de hecho una nueva forma de ley, porque, al igual que las leyes, configuran lo que la gente puede y no puede hacer ${ }^{5}$. Un mundo en el cual no siempre sabemos quién decide qué y según qué procedimientos, y en cual el «ciudadano de la red» ni tan siquiera consiente de forma libre y consciente sobre esas leyes o normas que le son de aplicación.

Un segundo aspecto que subrayar desde este momento es que la red funciona hoy día, en toda su potencialidad y magnitud, precisamente sobre la base de los denominados «bienes comunes digitales $\rangle^{6}$, creados y desarrollados sin ánimo de lucro y con la finalidad de compartir, de comunicar a través de la red.

WordPress, software abierto para la gestión de contenidos (primero se usó para diseñar blogs y luego páginas web), los protocolos de transmisión TCP/IP (familia de protocolos de internet que permite la transmisión de datos entre computadoras), las licencias de bienes Creative Commons (que facilitan al autor de una obra permitir al público en general compartir y usar su trabajo creativo) sobre las que se articulan, por ejemplo, Wikipedia, Linux (que debe su nombre precisamente a Linus Torvalds, ingeniero de software finlandés), o una serie de organismos como ICANN (Corporación de Internet para la Asignación de Nombre y Números, ICANN por sus siglas en inglés, que coordina los nombres de todos los dominios de internet), se crearon bajo esta fórmula de «bienes comunes digitales», y constituyen hoy día buena parte de los recursos de los que dispone cualquier usuario de la red $^{7}$.

En el fondo, como observa Escaño, apoyándose en las ideas de John Ryan $^{8}$, en este ámbito se produce un conflicto (que se advierte en el caso de los bienes comunes digitales incluso antes de la creación de internet) entre la fuerza «centrífuga» representada por el tejido digital procomunal, y la

${ }^{5}$ Lawrence Lessig, Código y otras leyes del ciberespacio. Traducción de José Ernesto Alberola Blázquez (Madrid: Taurus Digital, 2001).

${ }^{6}$ Como señalaron Ostrom y Hess, el estudio de los bienes comunes del conocimiento es reciente, pues se remonta a la década de los noventa del pasado siglo, extendiéndose a los comunes del conocimiento digital desde la eclosión del fenómeno www. Vid., Charlotte Hess y Elinor Ostrom (Eds.) Understanding Knowledge as a Commons, (Cambridge, Massachusetts: The MIT Press, 2007).

7 Vid., Rebecca Mackinnon, No si nuestro consentimiento. La lucha mundial por la libertad en internet. Traducción de Javier San Julián (Barcelona: Ediciones Deusto, 2012), 52-54.

${ }^{8}$ Vid., Johnny Ryan, A history of the Internet and the digital future (Chicago: The University of Chicago Press, 2010). 
«centrípeta» que se encarna en «la capitalización cognitiva, la cual opera en el presente de nuestra sociedad red privando al futuro de una experiencia epistemológica que pertenece a todo el conjunto de la sociedad $»^{9}$. Ello tiene por consecuencia que por parte de determinados poderes se tienda hacia el «cercamiento del conocimiento», los cercamientos digitales de los bienes comunes $^{10}$.

En cualquier caso, a nuestro juicio, la libertad de comunicación de ideas, el compartir, fueron la clave de la creación de internet tal y como la conocemos, y constituyen, por así decirlo, sus señas de identidad. Sostiene Rebecca MacKinnon que «los bienes comunes digitales son el equivalente virtual de la sociedad civil de Tocqueville, a través de los cuales los ciudadanos pueden movilizarse para expresar sus intereses y proteger sus derechos» ${ }^{11}$. Como escribe Enrique Dans «la red no discrimina absolutamente nada con respecto a los contenidos: trata exactamente igual lo escrito por un particular que la creación de una gran empresa. Ambos son paquetes de bits, y ambos circulan por la red con los mismos privilegios. La neutralidad es una característica definitoria y fundacional de la red. Internet es por naturaleza abierto y libre, y lo es para todos, porque estableció sus características en torno a un protocolo que consagraba la más absoluta y radical neutralidad, y que tiene como norma de identidad transmitir ciegamente un mensaje entre un origen y un destino» ${ }^{12}$.

Así, el fenómeno internet encaja plenamente, en el sentido que acabamos de apuntar considerado como medio de comunicación y transmisión de todo tipo de contenidos, en lo dispuesto (muchos años antes de que internet existiera) en el artículo 19 de la Declaración Universal de los Derechos del Hombre: «Todo individuo tiene derecho a la libertad de opinión y expresión; este derecho incluye el no ser molestado a causa de sus opiniones, el de investigar

${ }^{9}$ Carlos Escaño, «Bienes Comunes del Conocimiento: Una propuesta de desarrollo histórico del procomún digital», Opción, Revista de Ciencias Humanas y Sociales, Año 33, $\mathrm{n}^{\circ} 82$ (2017): 239-262. La cita es a la página 259.

${ }^{10}$ Escaño González, «Bienes Comunes del Conocimiento: Una propuesta de desarrollo histórico del procomún digital», 246. Escribe Carlos Escaño, que «hoy se ha desarrollado un aparato jurídico-legal que fortalece el ejercicio privatizador de bienes comunes inmateriales por parte de (...) señores de corporaciones «feudales» del conocimiento, es decir, con contratos que hacen de la acción intelectual un bien exclusivo, cosificándola y extendiendo una estructura de acuerdos internacionales multilaterales para el aprovechamiento de tales tierras digitales comunales», 246-247.

11 Mackinnon, No sin nuestro consentimiento...,51.

12 Enrique Dans, Todo va a cambiar. (Edición social), Cap. V, Introducción a la red. La neutralidad de la red. Disponible en https:/www.todovaacambiar.com/capitulo-5-introduccion-a-la-red-la-neutralidad-de-la-red, último acceso 23 de mayo 2018. 
y recibir informaciones y opiniones, y el de difundirlas, sin limitación de fronteras, por cualquier medio de expresión».

Al menos por el momento.

\section{LA DENOMINADA «NEUTRALIDAD EN LA RED»}

\section{Concepto y planteamiento del problema}

En términos muy generales, se puede definir la neutralidad en la red como el hecho de dar el mismo trato a todo el tráfico que circula por la red. Esta idea central implica que no se puede bloquear, retrasar o posponer el acceso a determinados destinos en la red, o a determinadas aplicaciones. El principio opera también justo en la otra dirección: no se podría priorizar o favorecer de algún modo el acceso a algún determinado proveedor de contenidos o servicios, o a alguna aplicación. Así se asegura que, desde un inicio, todos los proveedores de servicios parten de la misma posición para ofrecer sus servicios a los potenciales clientes, los internautas. Básicamente, como hemos señalado con anterioridad, así es como ha funcionado internet desde su creación.

En el ámbito jurídico-político de la Unión Europea, el BEREC (Organismo de Reguladores Europeos de Comunicaciones electrónicas, BEREC por sus siglas en inglés) ofrece una definición ${ }^{13}$ (más bien descriptiva) del principio de neutralidad en la red: «todo el tráfico que circula por una red es tratado de forma igual, independientemente del contenido, la aplicación, el servicio, el dispositivo o la dirección del que lo envía o recibe». Se trata, como se puede apreciar a primera vista, de una definición amplia, al incluir de una parte aplicaciones, servicios y contenidos; de otra, cualquier tipo de dispositivo (esto es, incluye los teléfonos móviles y sus sucesores, los teléfonos inteligentes o «smartphones», o las «tablets», y no solo los ordenadores fijos o móviles) y por último, es bidireccional o recíproca, pues opera tanto en un sentido (del usuario al proveedor) como en el otro (del proveedor al usuario).

Sin perjuicio de lo anterior, no es menos cierto que el concepto de neutralidad en la red está lejos de ser pacífico entre la doctrina. Como es sabido, la expresión net neutrality (neutralidad de la red) fue usada por primera vez en 2003 por el profesor de Derecho de la Universidad de Columbia Tim Wu, en

${ }_{13}$ Accesible a través de https://blog.cnmc.es/2016/06/06/el-berec-y-la-neutralidadde-la-red/ último acceso 25 de junio 2018. Las guidelines que el BEREC publicó en junio de 2016 están disponibles en https://berec.europa.eu/eng/document_register/subject_matter/berec/public_consultations/6075-draft-berec-guidelines-on-implementation-by-national-regulators-european-net-neutrality-rules, último acceso 29 de noviembre 2017. 
el ensayo titulado Network neutrality, broadband discrimination ${ }^{14}$, cuando a finales de los noventa del pasado siglo se comenzó a debatir, en Estados Unidos, sobre la gestión del tráfico de datos y de la calidad del servicio en internet (QoS, Quality of Service) con relación a la televisión por cable, cuyo modelo cerrado se temía que conquistase el internet abierto ${ }^{15}$. Wu no ofrece una definición precisa de neutralidad en la red, pero indica algunos de los elementos que la componen, como la promoción de la innovación en manos de los usuarios y su regulación como una norma de no discriminación ${ }^{16}$. Como precisa Castañeda Sabido ${ }^{17}$, Wu establece como neutralidad de red el derecho general del usuario a la utilización irrestricta de la red. En este sentido, ni la autoridad regulatoria ni el proveedor de servicios pueden restringir el uso de la red siempre y cuando dicho uso no sea ilegal o dañe la red.

Nicholas Economides ${ }^{18}$, por su parte, plantea la neutralidad de la red como un esquema en el que no se discrimina en el precio (o de alguna otra forma) entre paquetes (o bits), ni en la identidad del generador de contenidos o del usuario. La diferencia entre ambos autores es que Wu permite la discriminación de precios (se entiende establecida por los proveedores de acceso a internet, implantando así una «doble velocidad» en la red según los usuarios accedan a pagar o no) pues no establece restricciones en cuanto a esta cuestión. Las diferentes definiciones, advierte Castañeda, tienen distintos alcances: la definición de Economides asume implícitamente una arquitectura abierta y no propietaria de los protocolos y establece explícitamente la prohibición de discriminar en precios sobre la base del tipo de contenido o el proveedor o usuario al que va destinado el contenido. No prohíbe, sin

${ }^{14}$ Tim $\mathrm{Wu}$, «Network neutrality, broadband discrimination», Journal of Telecomunications and High Tecnology Law, Colorado, v.1, $\mathrm{n}^{\mathrm{0}} 2$, (2003): 141-149.

${ }_{15}$ Christopher T. Mardsen, «Neutralidad de la Red: Historia, regulación y futuro», «VII Congreso Internacional Internet, Derecho y Política. Neutralidad de la red y otros retos para el futuro de Internet» [monográfico en línea]. En IDP, Revista de Internet, Derecho y Política, Revista de los Estudios de Derecho y Ciencia Política de la UOC, número 13, (febrero 2012): 24-42, cita a la p. 26. Disponible en http://idp.uoc.edu/ojs/index.php/ idp/article/view/n13-marsden_esp/n13-marsden_esp, última consulta 28 agosto 2018

${ }^{16}$ Bernadette Califano, «Políticas de internet: la neutralidad de la red y los desafíos para su regulación», Revista Eptic Online, Vol. 15, n³, sept-dez, (2013): 19-37, la cita es a la p. 21. Disponible en http://e-tcs.org/wp-content/uploads/2017/03/Califano-2013Pol\%C3\%ADticas-de-Internet-la-neutralidad-de-la-red-y-los-desaf\%C3\%ADos-para-suregulaci\%C3\%B3n.pdf, última consulta 29 de agosto de 2018.

${ }_{17}$ Alejandro Castañeda Sabido, «Análisis de la literatura teórica sobre neutralidad de red y sugerencias de política», EconoQuantum, Zapopan, v. 6, nº1, (enero 2009): 31-57. Disponible en http://www.scielo.org.mx/scielo.php?script=sci_arttext\&pid=S1870$22009000200003 \& \operatorname{lng}=$ es\&nrm=iso, accedido el 2 de septiembre de 2018.

${ }_{18}$ Nicholas Economides y Joacim Tåg, «Net Neutrality on the Internet: A Two-Sided Market Analysis», Information Economics and Policy, no 24 (2012): 91-104. 
embargo, la integración vertical ${ }^{19}$. La definición de $\mathrm{Wu}$ no prohíbe la integración vertical y también asume implícitamente una arquitectura abierta de la red, aunque sí permite la discriminación de precios. Para $\mathrm{Wu}$, las prácticas excluyentes quedarían controladas por la legislación antitrust. Economides, sin embargo, aboga abiertamente por una legislación explícita de neutralidad de red, ya que considera que la legislación antitrust tardaría mucho tiempo en surtir efecto, pues implicaría la resolución de largos litigios ${ }^{20}$.

Quizá por ello entre la doctrina española Rodríguez Prieto ha llamado la atención sobre el concepto de «imparcialidad» en la red frente al de «neutralidad $»^{21}$. Calificar la red como imparcial, escribe, «en vez del comúnmente utilizado, neutral, es distinto. La neutralidad tan solo resuelve una parte del problema. La no interferencia de proveedores de acceso a la Red en el tráfico de esta y en las posibilidades del usuario de acceder a diferentes operadores de contenido. Pero deja desatendido el problema de la concentración de la propiedad en la Red, y por tanto el abuso de posición dominante, la mercantilización de los datos de los ciudadanos o el control sobre los mismos $\gg{ }^{22}$.

En suma, se puede afirmar que en términos generales hay dos posturas opuestas al respecto del tratamiento normativo del principio de neutralidad en la red $^{23}$. De una parte, la de quienes sostienen que es preciso regular de forma legal el principio de neutralidad en la red, pues el no hacerlo conllevaría (dada la situación de preponderancia en que se encuentran normalmente en el mercado las empresas proveedoras de acceso a la red) una seria amenaza a la libertad de expresión (entre otros muchos derechos) de los usuarios de internet. Por otra parte, los que se oponen a la regulación legal (fundamentalmente las empresas de telecomunicaciones que gestionan el tráfico en la red y son propietarias de las costosas infraestructuras necesarias para ello), alegan que la normativa en este ámbito detendría las inversiones de los proveedores de acceso e impediría la innovación y la reinversión en el sector.

${ }_{19}$ Es decir, en la práctica, la posibilidad de que los ISP (proveedores de acceso a internet $\mathrm{u}$ operadores de red) y los proveedores de contenidos, servicios o aplicaciones, estén participados o controlados por una misma empresa.

${ }^{20}$ Castañeda, «Análisis de la literatura teórica sobre neutralidad de red y sugerencias de política», 38 .

${ }^{21}$ Rafael Rodríguez Prieto, «De la «neutralidad» a la «imparcialidad» en la red. Un análisis crítico de la política de la UE sobre internet y algunas propuestas de mejora», Cuadernos Europeos de Deusto, Núm. 57 (2017): 217-246. Disponible en http://ced.revistas.deusto.es, último acceso 20 de agosto 2018.

${ }^{22}$ Rodríguez Prieto, «De la «neutralidad» a la «imparcialidad» en la red. Un análisis crítico de la política de la UE sobre internet y algunas propuestas de mejora», 242.

${ }^{23}$ Califano, «Políticas de internet: la neutralidad de la red y los desafíos para su regulación», 22. 
La primera postura, es la que $\mathrm{Wu}$ califica como openist, y reivindica el paradigma de «extremo a extremo» (end to end, «e2e») como antecedente del principio de neutralidad. Es el principio en que se basó internet en sus orígenes, como puso de manifiesto Lawrence Lessig ${ }^{24}$.

La segunda postura, que se conoce como desregulationis $t^{25}$, esgrime que las empresas solo invertirán en las redes de comunicaciones si pueden esperar beneficios razonables a su inversión. Las principales impulsoras de esta idea son, precisamente, las grandes empresas de telecomunicaciones propietarias de los ISP (Proveedores de Servicios de Internet) y que aspiran a controlar también (en una suerte de integración vertical «hacia atrás») la propiedad de los proveedores de contenidos, servicios o aplicaciones. Desde estos sectores se llega a calificar el debate sobre la neutralidad de red como «interesado sobre los derechos de los usuarios» ${ }^{26}$ ya que los derechos de los usuarios, se sostiene, no pueden ponerse en cuestión por las operadoras, pues esto iría contra su propio interés de negocio. Palazuelos y Herrera escriben al respecto que «por esto mismo es un debate carente de sentido: los operadores seguirán facilitando el acceso el acceso a todo tipo de información y servicios a sus usuarios (...). Los operadores de telecomunicaciones, entre ellos Telefónica, están a favor de la neutralidad de red, que defenderán con tanto o más ahínco que sus clientes $)^{27}$.

Obviamente, las implicaciones del principio de neutralidad son globales y transversales: afecta a la libertad de expresión, de información, de participación política, a la libre competencia en el mercado, al concepto de red abierta, al de brecha digital.... Y desde otro punto de vista implica multimillonarios intereses económicos transnacionales de grandes grupos de empresas ${ }^{28}$.

Así, el protagonismo de esta problemática está dominado (en el contexto emisor-mensaje-receptor, o «end to end», esto es «e2e») por las empresas

${ }^{24}$ Lawrence Lessig, Future of Ideas: the fate of the commons in a connected world (New York: Random House, 2001). Disponible en http://www.the-future-of-ideas.com/ download/, último acceso 19 de septiembre de 2018.

${ }_{25}$ Ambas calificaciones, en Tim $\mathrm{Wu}$, «The Broadband debate, a user's guide», Journal of Telecomunications and High Tecnology Law, Colorado, v. 3, nº 69 (2003): 69-96.

${ }_{26}$ María del Mar Palazuelos y Fernando Herrera, «La neutralidad de red. Un debate interesado sobre los derechos de los usuarios», Revista TELOS (Cuadernos de Comunicación e Innovación), Fundación Telefónica, Madrid, nº 82 (marzo 2010): 1-12.

${ }^{27}$ Palazuelos y Herrera, «La neutralidad de red. Un debate interesado sobre los derechos de los usuarios», 11 .

${ }^{28}$ Con carácter general, y referido al impacto de las nuevas tecnologías en la información, y sobre todo en la economía, es necesario citar la extensa obra de Manuel Castells, particularmente el vol. I, de La Era de la Información: economía, sociedad y cultura. La sociedad red (Madrid, Alianza Editorial, 2000). 
proveedoras de servicios, aplicaciones y contenidos de internet (por ejemplo Google, Youtube, Yahoo, Netflix, WhatsApp, etc.) que son las «generadoras» de la información o mensajes; por las operadoras de red o proveedores de acceso a internet (ISP por sus siglas en inglés, que son normalmente empresas de telecomunicaciones encargadas de hacer llegar el mensaje al receptor, de «transportar los paquetes de bits», por ejemplo Movistar, Orange, Jazztel, Ono, Vodafone, Telecable, etc.) y, por último, por los usuarios finales o consumidores de servicios. En paralelo, habría que tener también en cuenta las diversas autoridades gubernamentales (generalmente de carácter administrativo) tanto a nivel nacional o supranacional. Cada uno de estos actores (gobiernos, proveedores de servicios, ISP, usuarios) trata de imponer sus intereses en una dinámica que propicia, además, variables alianzas entre unos u otros, y en la que ninguno de ellos es sincero siempre y en todo momento. La neutralidad en la red, tal y como la entendemos en este documento, se refiere pues al debate sobre la forma, términos y condiciones en que los proveedores de servicios de internet gestionan el tráfico en sus redes o cuando se intercambia tráfico entre los usuarios finales.

En la práctica, como Rebecca MacKinnon sostiene, siguiendo a Lessig, las empresas de internet y de telecomunicaciones crean códigos informáticos que funcionan de hecho como una ley, como una norma, de modo que configuran qué es lo que la gente puede hacer y, a veces, censuran directamente lo que se puede ver. En ocasiones, el código informático está escrito para cumplir con las exigencias del gobierno, como en el caso chino. En otros casos, el gobierno usa el código legislativo, la ley, para forzar la evolución del código informático en una dirección u otra. A veces, estas leyes reflejan el «consentimiento de los gobernados»y otras veces no. Pero en todo caso, el código legislativo no cubre la mayoría de los aspectos del código informático. Por otra parte, ni los ciudadanos ni las empresas están interesados en una micro gestión excesiva del código informático desde un punto de vista normativo (en cuyo caso la innovación sería imposible). Así, la mayoría de las veces las empresas aplican sus propios criterios basándose fundamentalmente en factores comerciales. Desafortunadamente, el impacto de estas decisiones en la capacidad de los consumidores para ejercer sus derechos políticos y libertades es, en el mejor de los casos, algo secundario, si es que la cuestión llega a plantearse ${ }^{29}$.

En suma, una red neutral implica un acceso en idénticas condiciones para todos los usuarios, independientemente del poder económico de los agentes vinculados. El concepto de neutralidad situaría así a internet al nivel de servicios tan básicos como el agua: al abrir el grifo, el recurso llega igual para

${ }^{29}$ Mackinnon, No sin mi consentimiento..., 168. 
todos sin discriminaciones ${ }^{30}$. Si internet dejara de ser neutral, como plantean algunas operadoras, el usuario tendría un acceso mucho más rápido o lento a los contenidos que busca en la red, dependiendo de si las empresas que ofrecen los mismos hubieran pagado o no un canon por ellos.

\section{Ataques al principio de neutralidad. La gestión del tráfico en internet}

Como hemos observado, internet comenzó a expandirse mundialmente bajo el paradigma de la comunicación «end to end» («e2e», de extremo a extremo), basado en las ventajas de una red abierta, pero que en ocasiones ofrecía, apunta Marsden, «las desventajas de la congestión, de la fluctuación $\mathrm{y}$, en último término, una tasa decreciente de progreso para las aplicaciones finales de gama alta, como el vídeo de alta definición $»^{31}$. Efectivamente, es un hecho notorio que en momentos puntuales la red sufre problemas de «congestión» o «saturación», como ocurre en las vías de entrada o salida de las grandes ciudades en determinados periodos. El problema, según algunos, se hace más grave en la «última milla», es decir, en la entrega del paquete de datos al usuario final. Es en este momento donde surge el estrangulamiento de la red que, para algunos sectores, requiere la renovación del viejo protocolo http por otros nuevos. Parece lógico entonces priorizar ciertos contenidos o servicios como las emergencias médicas, o de seguridad.

Parte del problema comienza cuando los avances tecnológicos permiten a los ISP conocer el contenido del paquete de datos que transmiten, lo que no ocurría con anterioridad. Esto es posible gracias a la técnica denominada «inspección profunda de paquetes» (deep packet inspection, DPI). Como indica Marsden «los ISP no solo eliminan mensajes basura y otros materiales peligrosos antes de que lleguen a los subscriptores (que son técnicamente legos), también pueden eliminar otros materiales potencialmente ilegales en interés de los gobiernos y los titulares de derechos de autor, por nombrar a dos de los censores más activos en internet, así como priorizar paquetes en beneficio propio. En consecuencia, el principio e2e se vería amenazado, si no estuviera ya moribundo ${ }^{32}$. Por eso, argumenta el citado autor, la neutralidad

${ }^{30}$ Así se expresaba Víctor Salgado, responsable del despacho Pintos y Salgado Abogados, disponible en https:/www.elconfidencial.com/tecnologia/2015-02-28/asi-tehabria-afectado-perder-la-neutralidad-de-la-red_719757/, último acceso 7 de enero 2018. Podría ocurrir que un navegador, tipo Google o Bing, o cualquier otro, suministrara muy lentamente ciertos contenidos simplemente porque la empresa vinculada a los resultados buscados no hubiera contribuido con ese canon a las operadoras, o que las noticias de un diario se agilizaran al ser publicadas en el buscador, por haber pagado previamente por ello.

31 Marsden, «Neutralidad de la Red: Historia, regulación y futuro», 27.

32 Marsden, «Neutralidad de la Red: Historia, regulación y futuro», 25. 
de la red es un tema políticamente más importante de lo que las autoridades de regulación de telecomunicaciones están preparadas o legalmente obligadas a examinar, ya que están en juego tecnologías de censura ${ }^{33}$. Como apunta Ramírez Morán «si las cuestiones relacionadas con la neutralidad se limitaran a factores técnicos, tecnológicos, de transparencia y de políticas de priorización de tráfico, sería un asunto circunscrito a la regulación del funcionamiento de las operadoras y los proveedores de servicios $»^{34}$.

En un mundo globalizado, el problema se agudiza en dictaduras, países autoritarios y democracias en vías de consolidación, donde la red, por definición, no es neutral. Los ataques a la neutralidad de la red adoptan, en consecuencia, diversas formas y grados de intensidad. Desde la censura directa de contenidos o de acceso a determinadas páginas webs, hasta otros más sutiles, como las llamadas ofertas de «zero rating», que permiten seguir navegando gratis por la red, pero solo para acceder a determinados servicios (normalmente, de proveedores de contenidos que han pagado al efecto al proveedor de acceso a la red). Como indica Mackinnon, los ciudadanos son, por tanto, susceptibles de ser víctimas de abusos en sus derechos de expresión o reunión, no solo por parte del gobierno, sino también por actores privados ${ }^{35}$.

La panoplia de situaciones concretas es tremendamente variada. En China (mercado que Apple se vio obligada a abandonar por las censuras impuestas por el gobierno) donde existen buscadores propios, como Baidu y redes sociales chinas, el mercado de las telecomunicaciones funciona bajo un régimen de requerimiento de autocensura corporativa que se aplica a todas las páginas webs chinas y que paradójicamente es compatible, según el propio gobierno chino, con la «democracia en internet» ${ }^{36}$ al estilo chino. Min Jian califica la situación como de "deliberación autoritaria» ${ }^{37}$, en el sentido de que, en China, es el estado quien establece los límites del discurso político.

En Rusia, (también con su internet en lengua rusa «Runet» y motor de búsqueda autóctono «Yandex») el gobierno no filtra directamente internet como lo hace China, pero los usuarios de la red sufren restricciones y son manipulados con una amplia variedad de lo que los investigadores de la Open Net Iniciative, señala Mackinnon, llaman «controles de internet de tercera

${ }^{33}$ Marsden, «Neutralidad de la Red: Historia, regulación y futuro», 33.

${ }^{34}$ David Ramírez Morán, «Luces y sombras de la neutralidad en la red». Ieee.es Instituto Español de Análisis Estratégicos, Documento de Análisis 15/2015, 11 de marzo de 2015, disponible en http://www.ieee.es/temas/ciberseguridad/2015/DIEEEA15-2015. html, último acceso 24 de octubre 2017.

${ }_{35}$ Mackinnon, No sin mi consentimiento..., 172 y ss.

${ }^{36}$ Mackinnon, No sin mi consentimiento..., 83.

37 Min Jiang, «Authoritarian Deliberation on Chinese Internet», Electronic Journal of Communication, 20, (2010), disponible en https://papers.ssrn.com/sol3/papers.cfm?abstract_id=1439354, último acceso 3 de octubre de 2018 
generación», que incluyen el control, los ciberataques, y la manipulación proactiva del discurso público on line ${ }^{38}$.

La situación dista igualmente de ser deseable en el mundo islámico. Según Howard, citado por Mackinnon, la manera en que los gobiernos gestionan las tecnologías de internet y telefonía tiene gran impacto en las posibilidades de que se produzcan cambios políticos ${ }^{39}$, pero lo cierto es que en Irán se bloquean millones de páginas webs ${ }^{40}$, o que los gobiernos censuraron abiertamente la red durante la «primavera árabe» ${ }^{41}$, o que la falta de neutralidad también incide gravemente en el uso del teléfono móvil o inteligente (smartphone) pues además estos dispositivos están mucho más ligados a un usuario específico que un ordenador. Las empresas de telefonía móvil, que funcionan como proveedores de servicios de internet en muchos países, pueden identificar sin problema al usuario del teléfono a través de su IMEI (número de identificación de equipo internacional móvil, por sus siglas en inglés) o su número de tarjeta SIM o del propio número de teléfono. Un recurso peligroso en manos de un estado no democrático.

\section{LOS PRINCIPIOS INSPIRADORES DE LAS SOLUCIONES NORMATIVAS SOBRE LA NEUTRALIDAD EN LA RED}

Frente a esta diversidad de situaciones, nos centraremos ahora en los dos principales modelos de soluciones normativas ${ }^{42}$ que se han dado a esta problemática, las que provienen de los Estados Unidos y de la Unión Europea, sin que se trate ni mucho menos, de un debate cerrado, sobre todo en Estados Unidos. Ambos sistemas representan dos modelos teóricos de abordar normativamente la cuestión, y provienen de sociedades democráticas donde

38 Mackinnon, No sin mi consentimiento..., 113.

39 Apud, Mackinnon, No sin mi consentimiento..., 96. Vid., Philip M. Howard, The Digital Origins of Dictatorship and Democracy: Information Technology and Political Islam (Nueva York: Oxford University Press, 2010): 10 y ss.

40 Vid.,v.gr.,https://elpais.com/tecnologia/2012/02/10/actualidad/1328873270_653423. html, último acceso 26 de septiembre de 2017.

${ }^{41}$ Vid., v. gr., Juan Antonio Cordero Fuentes, «Los regímenes árabes contra Internet durante la «primavera árabe»: los casos de Egipto, Libia y Siria», en Seguridad y conflictos: una perspectiva multidisciplinar, coord. por Miguel Requena y Díez de Revenga (Madrid: Instituto Universitario General Gutiérrez Mellado, 2012), 367-404.

${ }^{42}$ Lo cierto es que el primer país del mundo en promulgar una normativa específica sobre neutralidad de la red fue Chile, que consagra el principio de neutralidad en la ley $\mathrm{N}^{\mathrm{o}}$ 20453, de 26 de agosto de 2010. Poco después, Holanda hizo lo propio, y en sentido análogo. Canadá, por ejemplo, ha carecido durante mucho tiempo de normativa específica al efecto, si bien desde 2008 la Comisión Canadiense de Radiodifusión y Telecomunicaciones, CRTC, se ocupa de velar por el principio de neutralidad. 
existe un notable nivel de respeto de los derechos humanos; la cuestión (irresoluble por el momento) es determinar si finalmente se impondrá a nivel global un modelo u otro.

\section{Estados Unidos: de la aparente neutralidad a un futuro incierto}

En los Estados Unidos de Norteamérica el debate sobre la gestión del tráfico de datos en internet constituye actualmente casi una cuestión de Estado ${ }^{43}$. Muy apretadamente, podemos resumir que en el año 2007 el entonces candidato a la presidencia del país, Barak Obama de posicionó expresamente a favor de la neutralidad de la red en un debate en la Universidad de Coe (Iowa) ${ }^{44}$. Siendo ya presidente, en 2009, la todopoderosa Comisión Federal de Comunicaciones, FCC (Federal Communications Commission) dictó reglas que obligaban a los ISP a aplicar el principio de neutralidad en la red. A consecuencia de ello Comcast (uno de los mayores proveedores de internet por cable) demandó judicialmente la situación, al alegar, básicamente, que la FCC carecía de competencia para obligar a la compañía a gestionar su tráfico de datos de un modo determinado. En 2010, la Corte Federal falló a favor de Comcast, al tiempo que la FCC publicó un documento ${ }^{45}$ en el que se resumen las bases de la protección de una red abierta:

Transparencia: Los proveedores de banda ancha deberán de informar sobre sus prácticas de gestión de red y sobre los términos comerciales de sus servicios.

No bloqueos: Los proveedores de banda ancha no pueden bloquear contenidos reconocidos como legítimos, aplicaciones, servicios o dispositivos no perjudiciales.

No discriminación sin motivos: los proveedores de banda ancha no podrán discriminar sin razón las transmisiones de red legales ${ }^{46}$.

${ }^{43}$ De hecho, la legislación proneutralidad la impulsó George W. Bush y la reforzó Obama. En contra, Ramírez Morán, para quien «si bien Estados Unidos se ha centrado en la componente más tecnológica del servicio, en la Unión Europea se han incluido otros factores indirectamente relacionados», «Luces y sombras de la neutralidad en la red», 12.

44 Vid., Anne Broache, Obama pledges net neutrality laws if elected president. Disponible en https://www.cnet.com/news/obama-pledges-net-neutrality-laws-if-elected-president/_Octubre 2007, última consulta 11 de setiembre 2017.

45 FCC. «In the matter of preserving the open internet broadband industry practice», disponible en http://transition.fcc.gov/Daily Releases/Daily Business/2010/db1223/FCC10-201A1.pdf, Setiembre 2011, última consulta 27 de agosto 2018.

46 Vid., José Luis Martínez Sugastti, «Neutralidad de la Red», disponible en http:// jeuazarru.com/wp-content/uploads/2014/10/Neutralidad_de_red.pdf, última consulta 3 de septiembre 2018. 
En 2015, la FCC (presidida entonces por Tom Wheeler) estableció que los ISP no podrán tomar medidas que interfieran de modo poco razonable o que perjudiquen a los consumidores o a las empresas dueñas de las aplicaciones ${ }^{47}$. Como mucho, podrían frenar los servicios solo con objetivos de «gestión razonable de la red», pero nunca por motivos comerciales. Sin embargo, en abril de 2017, el nuevo presidente de la FCC, Ajit Pai, explicó que internet de alta velocidad no debía de ser tratado como un servicio público sujeto a unas reglas estrictas como hasta ahora ${ }^{48}$. Debe de ser el propio sector el que se autorregule según sus necesidades, pues en el fondo se estima que la neutralidad de la red no es buena para los negocios. Si la neutralidad es vencida en Estados Unidos, Mackinnon sostiene que además de la reducción de opciones donde elegir para el usuario, también existe la pregunta de si estas políticas dirigirán al discurso político y al activismo hacia un puñado de grandes ${ }^{49}$ medios sociales comerciales, cuyos servicios probablemente serán escogidos a medida que los servicios favorecidos y gratuitos se dirigirán a los consumidores de bajo nivel adquisitivo ${ }^{50}$. La base del sistema en Estados Unidos era, pues, la consideración de internet como un «servicio público», naturaleza jurídica que le fue retirada ${ }^{51}$ el pasado 14 de diciembre de 2017, bajo el ejecutivo de Donald Trump. La cuestión estribaba en la reclasificación de los

${ }^{47} \mathrm{Vid}$. , https://www.fcc.gov/restoring-internet-freedom, último acceso 10 de octubre de 2018 .

48 Información disponible en https://www.adslzone.net/2017/04/27/estados-unidos-acabara-con-la-neutralidad-de-la-red-y-permitira-un-internet-de-dos-velocidades/, última consulta 22 de septiembre 2018 .

49 Información ofrecida por el diario español El País, edición de 15 de diciembre de 2017, disponible en edición digital https:/elpais.com/internacional/2017/12/14/estados unidos/1513217068_301815.html, último acceso 12 de septiembre de 2018. Como informa Jan Martinez Ahrens, quien firma la noticia, «derribado este blindaje, otra etapa evolutiva da comienzo. El operador, que hasta ahora no podía interferir en el tráfico de su autopista, ya puede crear carriles rápidos, lentos o directamente denegar la entrada. Aunque los proveedores no han hecho públicos sus planes, se abre la puerta a que negocien acuerdos con portales, a que puedan ofrecer paquetes de servicios de internet parecidos a los de las televisiones por cable, y que, a la postre, doten de mayor velocidad a sus asociados en detrimento de los que no. E incluso, según los expertos, que bloqueen a quienes compitan con sus ofertas. El caleidoscopio de escenarios es casi inagotable, pero se resume en la posibilidad de escalas de servicio y, por tanto, precios distintos para el usuario y también para las grandes compañías. Este último punto es especialmente delicado. Una queja antigua de los operadores es el gasto generado por los portales más grandes, cuyo uso masivo de datos acapara el ancho de banda. Esto puede dar pie a tarifas especiales, algo asumible posiblemente por Google, Amazon o Facebook, pero oneroso para nuevas empresas o aquellas en situaciones financieras precarias».

${ }^{50}$ Mackinnon, No sin mi consentimiento ..., 180.

${ }^{51} \mathrm{https} / /$ www.france24.com/es/20180612-estados-unidos-fin-neutralidad-internet, último acceso 22 de septiembre de 2018. 
ISP de banda ancha como servicios de información (information services), habiendo sido estos considerados hasta entonces common carriers services o servicios de transporte común sujetos a la Communications Act de 1934. La nueva regulación entró en vigor en junio de 2018, y en palabras del Sr. Pai «ahora, el 11 de junio, estas innecesarias y dañinas regulaciones de Internet serán derogadas y el enfoque bipartidista que funcionó en el mundo en línea durante 20 años será reestablecido» ${ }^{52}$. En la misma línea, «La retirada de la neutralidad supondrá restaurar la libertad, volver a un Internet mejor y más barato. Seguirá habiendo protección para el consumidor y su acceso no se verá limitado. Pero no es nuestro trabajo decidir quién gana y quién pierde en la economía de Internet. El gobierno dejará de regular sobre cómo los proveedores deben manejarse, y estos tendrán incentivos para afrontar la próxima generación de redes y servicios», dijo Pai.

\section{Unión Europea: el principio general de «neutralidad tecnológica»}

La solución normativa europea al problema de la neutralidad de la red pasa actualmente por el Reglamento 2015/2120 del Parlamento Europeo y del Consejo, de 25 de noviembre de $2015^{53}$, por el que se establecen medidas en relación con el acceso a una internet abierta. En términos muy generales, se puede afirmar que la Unión Europea ha consagrado un principio básico en esta materia: todos podemos comunicarnos con todos de la misma forma, sin discriminación alguna. Este es el principio general que inspira el Reglamento, seguido de una serie de excepciones (por concreción o determinación de este principio) basadas a nuestro juicio en el sentido común, y delegando las cuestiones hermenéuticas y de aplicación de la norma bien en el BEREC o en las respectivas autoridades nacionales. De hecho, en agosto de 2016 el propio BEREC publicó unas «guidelines» para orientar la implementación de la normativa comunitaria por parte de las autoridades nacionales ${ }^{54}$.

Así, en su Considerando $1^{\circ}$, el citado Reglamento establece que tiene por objeto «establecer normas comunes destinadas a garantizar un trato equitativo

${ }^{52}$ Información del Diario El Comercio, edición digital del diario matutino ecuatoriano disponible en https:/www.elcomercio.com/afull/neutralidaddelared-estadosunidos-internet-tecnologia-paraquecaches.html., último acceso 11 de septiembre de 2018.

${ }_{53}$ El origen más próximo de esta regulación se encuentra en el Paquete de Reformas de Telecomunicaciones que aprobó el Parlamento Europeo en noviembre de 2009. Allí se reconocía el acceso a internet como un derecho fundamental del ciudadano. Es cierto que en mayo de 2001 el Presidente Sarkozy se mostró favorable a la regulación de internet, un mes antes de que Holanda aprobara legalmente la neutralidad de red. El Reglamento está disponible en https://www.boe.es/doue/2015/310/L00001-00018.pdf

${ }^{54} \mathrm{http} / /$ eur-lex.europa.eu/legal-content/EN/TXT/PDF/?uri=CELEX:32015R2120\&from=EN, último acceso 7 de octubre 2018 . 
y no discriminatorio del tráfico en la prestación de servicios de acceso a internet y a salvaguardar los derechos de los usuarios finales». Y en su Considerando $2^{\circ}$ afirma que «las medidas previstas en el presente Reglamento respetan el principio de neutralidad tecnológica, es decir, no imponen el uso de ningún tipo particular de tecnología ni discriminan a su favor» ${ }^{55}$.

El Reglamento de la UE opta, a nuestro juicio, por un modelo de internet fundamentalmente abierto, neutral y gratuito, de modo que los ISP no pueden gestionar el tráfico en sus redes para favorecer ciertos servicios ("gestión razonable del tráfico»); priorizar ciertos servicios por una supuesta congestión en sus redes («gestión excepcional del tráfico por congestión»); ofrecer un acceso privilegiado a «servicios especializados» al mismo tiempo que servicios de acceso a internet para eludir las reglas que garantizan la neutralidad de la red, ni dar acceso a algunos servicios de forma gratuita, injusta y anticompetitiva a la vez que cobran una tarifa a los clientes para descargar otros servicios $^{56}$ (zero rating). Las excepciones al régimen general serían aquellas cuya finalidad fuera la gestión del tráfico para cumplir con un requerimiento legal, para asegurar la integridad y seguridad de la red y para gestionar el acceso y/o congestión de categorías de tráfico equivalentes (esto es, que en ciertos casos unos servicios pueden tener «prioridad» respecto a otros) ${ }^{57}$.

El Reglamento, no obstante, indica Joe MacNamee, director de European Digital Rights, deja a las autoridades reguladoras la elaboración de una interpretación de la legislación que preservase un internet libre y abierto. Las grandes empresas de telecomunicaciones ya están presionando para que estas nuevas reglas se cambien, argumentando que este marco legal evitará el lanzamiento de la quinta generación de redes de comunicaciones móviles ${ }^{58}$ $(5 \mathrm{G})$.

55 Nótese que la norma se refiere, textualmente, al «principio de neutralidad tecnológica», que se entiende que es más amplio y engloba a la propia «neutralidad en internet». Así lo sostiene, por ejemplo, Espinosa. Vid., Carles Alfonso Espinosa, «La información en la red y el principio de neutralidad tecnológica: la libertad de expresión y la difusión de información administrativa», Revista Derecho del Estado, núm. 22, (junio 2009): 83-128. Disponible en http://www.redalyc.org/articulo.oa?id=337630232003, último acceso en 3 de febrero de 2018. «El principio de neutralidad tecnológica es un concepto mucho más amplio que el de neutralidad de la red, que sólo se refiere a la infraestructura lógica y económica de los servicios y productos informáticos». La cita es a la p.87.

56 Vid., Joe McNamee, «Europa gana, Internet sigue siendo libre», en El País, edición 31 de agosto de 2016, disponible en https://elpais.com/elpais/2016/08/31/opinion/1472639216_221713.html, último acceso 1 septiembre 2017.

57 Vid., art. 3.3 del Reglamento.

${ }^{58} \mathrm{McNamee}$, «Europa gana, Internet sigue siendo libre». Y añade que «El punto más flojo versa sobre el llamado zero rating. Aunque se trata de una práctica anticompetitiva, no se prohíbe de manera clara. Las autoridades competentes tendrán que evaluar cada oferta «a tipo cero» y tomar decisiones acerca de su legalidad una por una. Teniendo en 


\section{UN POSIBLE ARGUMENTO EN FAVOR DE LA LIBERTAD DE COMUNICACIÓN EN LA RED: EL «IUS COMMUNICATIONIS» DE FRANCISCO DE VITORIA}

Como es sabido, el teólogo dominico Francisco de Vitoria dedicó parte de sus Relectiones, en pleno S. XVI, a cuestiones suscitadas por el descubrimiento y colonización de América. En la primera «Relección De los Indios recientemente descubiertos» (De Indis recenter inventis relectio prior de Indis) probablemente escrita a finales de 1538, «o a más tardar en las primeras semanas de enero del $39 »{ }^{59}$, Vitoria cuestiona la legitimidad de los títulos de los españoles para fundar el dominio sobre los indígenas americanos, negando que los pueblos civilizados puedan dominar por derecho natural pueblos «bárbaros», pero reconociendo que pueden hacerlo por otras razones, en primer lugar, en virtud de la «sociedad y comunicación natural», por la que los españoles pueden viajar y residir en tierras indias, siempre que no se cause ningún mal ${ }^{60}$. Obviamente, los temas que trata Vitoria, aún con inicio en el ámbito de la teología moral, se extienden a cuestiones políticas y jurídicas ${ }^{61} \mathrm{y}$ el autor como tales las analiza.

En cualquier caso, la tesis de Vitoria sobre la sociedad y comunicación natural se funda a su vez en la existencia de ciertos bienes comunes por naturaleza. Como recuerda Añaños Meza, la idea de los bienes comunes es tan antigua como nuestra civilización ${ }^{62}$, y sigue presente en la actualidad, ya sea en su vertiente de bienes tangibles (el agua, los bosques, reservas pesqueras) como en su dimensión de bienes inmateriales o intangibles (precisamente

cuenta las tácticas utilizadas por los operadores de telecomunicaciones, estas decisiones serán a menudo recurridas ante los tribunales, incluso en casos en los que el resultado sea previsible. Esto significa que las start-ups tendrán miedo a quedarse fuera del mercado porque ofertas a tipo cero seguirán existiendo durante los meses y años que tarden las autoridades en tomar una decisión final».

59 José Beltrán de Heredia, Los manuscritos del maestro Fray Francisco de Vitoria. Estudio crítico e introducción a sus Lecturas y Relecciones (Madrid-Valencia: Tipografía Moderna, Madrid-Valencia, 1928), 144.

${ }^{60}$ Francisco De Vitoria, De Indis, en Relecciones Teológicas, Obras de Francisco de Vitoria, edición crítica del texto latino, versión española, introducción general e introducciones con el estudio de su doctrina teológico-jurídica por Teófilo Urdanoz, O.P. (Madrid, Biblioteca de Autores Cristianos, 1960), 641 y ss.

${ }^{61}$ Vid., v.gr., Guido Fassò, Historia de la Filosofía del Derecho, Vol. II $2^{\mathrm{a}}$ ed., traducción de José F. Lorca Navarrete, (Madrid, Ediciones Pirámide, 1981), 58 y 59.

${ }^{62}$ María Cecilia Añaños Meza, «La doctrina de los bienes comunes de Francisco de Vitoria», en Persona y Derecho, Vol. 68, (2013): 103-137, cita a la p. 104. Vid., también, de la misma autora, «El título de 'sociedad y comunicación natural' de Francisco de Vitoria. Tras las huellas de su concepto a la luz de la teoría del Dominio», en Anuario Mexicano de Derecho Internacional, vol. XII, (2010): 525-596. 
como el régimen de open access en la ciencia, el software libre o código abierto, el hardware libre...). Con anterioridad, hemos aludido a como internet fue creada precisamente bajo la idea de libertad y sobre la base de estos «bienes comunes digitales». El propio Berners-Lee declaraba en una entrevista en 1997 que ««si la Web fuera propiedad de una empresa, todo el mundo tendría que esperar a que el departamento de investigación de ella produjera la siguiente versión de su navegador, y esto no sería bueno. Para que algo como la Web exista y se expanda, tiene que basarse en estándares públicos y gratuitos. La red no debe tener dueño» ${ }^{63}$. Y en marzo de 2017, el ya Sir Tim Berners-Lee escribió una carta abierta ${ }^{64}$ en la que afirma que «imaginaba la web como una plataforma abierta que permitiría a todas las personas, en todas partes compartir información, tener acceso a oportunidades y colaborar más allá de límites geográficos y culturales».

Según Mackinnon, idealmente, los bienes comunes digitales, que incluyen fundamentalmente un conjunto de estándares técnicos y programas de software libre de código abierto, además de una amplia gama de medios de comunicación digitales, pueden coexistir en una relación positiva y simbiótica tanto con los gobiernos como con el sector privado ${ }^{65}$. Y Benkler, describe que internet es tanto el producto como la incubadora de «producción de información basada en bienes comunes, de individuos y organizaciones flexibles que generan información sin derechos de propiedad $\rangle^{66}$.

Vitoria, por su parte, recoge la tradición romana ${ }^{67} \mathrm{y}$ tomista ${ }^{68}$ sobre la teoría del dominio común iusnatural o comunidad de bienes, pero un aspecto digno a resaltar de la teoría vitoriana del origen del dominium, es, siguiendo

${ }^{63}$ Entrevista realizada por José Ángel Martos, publicada en el número 97, 1997, de la Revista Muy Interesante, y disponible en https:/www.muyinteresante.es/tecnologia/articulo/tim-berners-lee, último acceso 7 de octubre 2018.

${ }^{64}$ Disponible en https://webfoundation.org/2017/03/web-turns-28-letter/, último acceso 22 de septiembre 2018. Berners-Lee muestra su preocupación por tres problemas: La pérdida del control de sus datos personales por parte de los usuarios, la proliferación de noticias falsas en la red, y la necesidad de transparencia sobre la publicidad política en internet.

${ }_{65}$ Mackinnon, No sin mi consentimiento..., 52.

${ }^{66}$ Yochai Benkler, The Wealth of Networks, (New Haven: Yale University Press, 2007), 472.

${ }^{67}$ Así lo hace constar Marciano en un pasaje del Digesto, Dig. I, 8, 2, 1. Como cosas naturali iure communia ommnium abiertas al uso común de todos, señalaba el aire, el agua de los ríos y lluvias, los mares y sus costas. Vid., Cuerpo de Derecho Civil o sea Digesto, Código, Novelas e Instituta de Justiniano (Madrid: Imprenta de Ramón Vicente, 1872), 56. También Cicerón en De Officis, I, 21. Marco Tulio Cicerón, Los Oficios, Traducción de Manuel de Valbuena, (Madrid: Sociedad Española de Librería, 1928).

${ }_{68}$ Vid., Summa Teológica, II-II, q. 66 a.2. Tomás de Aquino, Suma Teológica, II-II, (Madrid: BAC, 2011). 
a Añañaos, que el dominium ommium natural de cada persona perdura después del pecado original, teniendo con ello los hombres un dominium ommium y, por tanto, siendo libres e iguales por derecho natural. Este dominium ommnium aparece o cobra validez en dos situaciones particulares. La primera, en los derechos de caza, pesca y provisión de leña, que solo deben de ser limitados por razones justificables; y la segunda, cuando alguien pierde sus bienes o se encuentra en estado de extrema necesidad, estando en ese caso el necesitado amparado por derecho natural a tomar lo necesario para cubrir sus necesidades ${ }^{69}$. Para el dominico español, como antes para Cicerón ${ }^{70}$, todo el género humano forma una comunidad fundada en la común naturaleza humana; esta sociedad ideal obliga moralmente a sus componentes, por mor del vínculo de la solidaridad humana, a compartir o ceder sus bienes a favor de los necesitados llegado el caso, y a hacer uso común de los bienes comunes.

Por lo que toca a los bienes comunes, como defiende Añaños, la doctrina vitoriana de los bienes comunes como verdadero fundamento del principio de naturalis societatis et communicationis ha permanecido «sin descubrir» en los comentadores de Vitoria, y por tanto no ha sido tampoco posible establecer conexión alguna entre ésta y la idea moderna de los bienes comunes ${ }^{71}$. Es por ello por lo que, en los debates actuales sobre los bienes comunes, del «patrimonio común de la humanidad», no se menciona a Vitoria, quien es en realidad su exponente más vasto y creativo ${ }^{72}$. Su doctrina de los bienes comunes es tan actual como relevante, no solo en lo que toca a los bienes tangibles (como pueden ser hoy día los fondos marinos o el espacio ultraterrestre), sino por lo que ahora nos ocupa, a los bienes intangibles ${ }^{73}$, que, habiéndose creado

69 Añaños, «La doctrina de los bienes comunes de Francisco de Vitoria», 114-115.

${ }^{70}$ Cicerón desarrolla ambas ideas en De Officis, Libro I, Cap. XVI. Para Cicerón, el género humano no sólo tiene en común el habla y la razón, sino que estos precisamente acercan y unen a los humanos en una sociedad natural. Y afirma que «todo cuanto podamos comunicar sin detrimento nuestro, debemos darlo aún al que no conocemos: de donde nacen aquellas obligaciones comunes de no estorbar el uso del agua corriente, permitir tomar lumbre de la nuestra a quien la quiera (...) Y así conviene que sea libre, y universal el uso de ellas, y contribuir siempre con algo de nuestra parte a la utilidad común». Cicerón, Los Oficios, 49 y ss.

71 Modernamente se suelen denominar «comunes», o «comunes del conocimiento», por influencia de la terminología anglosajona, que se refiere a ellos genéricamente como «commons». Vid., v.gr., Hees y Ostrom, Understanding Knowledge...

72 Añaños, «La doctrina de los bienes comunes de Francisco de Vitoria»,132.

${ }^{73}$ Philippe Aigrain señala que existe una gran diferencia entre los bienes comunes físicos y los bienes comunes de la información. Muchos de los primeros, por su propia naturaleza, son limitados y no renovables. Los segundos, en general, pueden ser reproducidos, difundidos y enriquecidos a un costo muy bajo, y además, cuantas más personas participen cooperativamente en su desarrollo, su valor aumenta. Vid., Philippe Aigrain, 
como comunes, constituyen el fundamento de internet tal y como fue creada y como de momento la conocemos. Como hemos reseñado páginas atrás, WordPress, los protocolos de transmisión TCP/IP, las licencias de bienes Creative Commons, Wikipedia, Linux, o el propio ICANN se crearon bajo la fórmula de «bienes comunes digitales», y hacen que internet sea lo que hasta ahora $\mathrm{es}^{74}$.

En este sentido, Figueroa entiende que en la actualidad «los bienes comunes de la información son sistemas donde se considera primordial el uso común y colectivo, así como la producción, difusión y preservación comunal para las generaciones actuales y futuras $\rangle^{75}$ resultando primordial su importancia para la construcción de una sociedad y cultura libres ${ }^{76}$.

En Vitoria, la naturalis societatis et communicationis, la «sociedad y comunicación natural» es uno de los principios fundantes del ius gentium natural, conforme al cual ha de organizarse la comunidad mundial (totus orbis) y de él derivan otros principios, como los de solidaridad, reciprocidad, humanidad y comunicación o participación de los bienes. Como tal principio de derecho natural, la sociedad y comunicación natural es universal, necesario, y obligatorio o imperativo, siendo sus consecuencias no solo

«The individual and the collective in open information communities», disponible en http://opensourde.mit.edu/papaers/aigrain3.pdf, último acceso 26 de septiembre de 2018.

${ }^{74}$ Escaño recoge en el artículo anteriormente citado hasta 25 «hitos tecnoculturales principales del procomún digital», desde 1945 (el artículo «As we may Think» de Vannevar Bush) hasta 2004 (la Free Culture Fundation) cada uno significativo por representar algún tipo de contribución al «procomún digital». Entre ellos, además de los ya citados en el presente texto, la propuesta Intergalactic Computer Network, de 1962, el proyecto francés CYCLADES, de 1972, Usente, de 1979, el concepto de Copyleft, de 1985, la red P2P, de 1996, las redes de capa anónima, operativas desde 2000-2003, entre ellas Tor, la Web 2.0, desde 2004. Escaño, «Bienes Comunes del Conocimiento: Una propuesta de desarrollo histórico del procomún digital», 251-259. A nuestro juicio resulta cuestionable la inclusión, sin matización alguna, de las redes de capa anónima como elemento que haya contribuido positivamente al procomún digital.

${ }^{75}$ Hugo Alberto Figueroa Alcántara, «Los bienes comunes de información en la era digital» en, El Conocimiento y la Información como factores de integración de América Latina, ed., por Estela Morales Campo (México, D.F., Instituto de Investigaciones Bibliotecnológicas y de la Información, Colección Seminarios de Investigación, 20, Universidad Autónoma de México, 2012): 19-43, versión digital disponible (artículo) en http://132.248.242.6/ publica/conmutarl.php?arch $=3 \& i d x=185$, último acceso 10 de octubre 2018. Disponible en línea también (libro) en, Biblioteca.clacso.edu.ar/Mexico/ uacm/20170516044723/pdf_135.pdf, último acceso 12 de octubre de 2018.

${ }^{76} \mathrm{Vid}$., Hugo Alberto Fígueroa Alcántara, «La importancia de los bienes comunes de información para una sociedad y cultura libres», en Memorias del $7^{\circ}$ Seminario Mexicano de Investigación en Bibliotecología y Documentación, ed. por Jaime Ríos Ortega y César Augusto Ramírez V, (México: CUIB, 2010) 597-611. https://www.ucm.es/.../129-201411-04-7_seminario_hispanomexicano_Publicación., último acceso 3 de febrero 2018. 
religiosas o morales, sino estrictamente jurídicas. Su único límite se encontraría en la obligación de no generar daño o detrimento a los demás.

De este principio general de derecho natural (naturalis societatis et communicationis) surgen en la obra de Vitoria tres derechos derivados: el ius peregrinandi (que otorga libertad a los extranjeros de transitar, inmigrar y residir en tierras extranjeras ${ }^{77}$ ) el ius negotiandi $i^{78}$ (que legitima el comercio de mercaderías), y, por último, el derecho de comunicación y participación de bienes comunes.

Para Vitoria, como recuerda Desantes-Guanter ${ }^{79}$, el ius communicationis es natural porque lo es la comunicación misma, pero la naturalidad de la comunicación no la explica en la Relectio Prior de Indis, porque ya lo hizo con anterioridad, en 1528, en la Relectio de potestate civili ${ }^{80}$. Es en De potestate civili donde afirma con rotundidad que «todos somos llevados por naturaleza a la comunicación, como Aristóteles observa $\rangle^{81}$, o que el hombre que rechazara la comunicación "dejaría de ser hombre»" ${ }^{82}$. Vitoria expone el hecho natural de la sociabilidad humana, por lo que Urdanoz pudo escribir que «la viva descripción vitoriana va calcada sobre los trazos eternos de cuadro aristotélico sobre el hombre como animal natural, social y político» ${ }^{83}$, pero que la sociabilidad humana no solo se desprende como inexorable exigencia de la condición física del hombre, sino también de todos los aspectos

77 Vid., De Indis, Relectio I, 3 (De los títulos legítimos por los cuales pudieran venir los bárbaros a poder de los españoles), 3-4, 708 y ss. «Si hay cosas entre los bárbaros que son comunes, tanto a los ciudadanos como a los huéspedes, no es lícito a los bárbaros prohibir a los españoles la comunicación y participación de esas cosas» (Tertia Propositio).

78 «Es lícito a los españoles comerciar con ellos, pero sin perjuicio de su patria, importándoles los productos de que carecen, y extrayendo de allí oro o plata u otras cosas en que ellos abundan; y ni sus príncipes pueden impedir a sus súbditos que comercien con los españoles ni, por el contrario, los príncipes de los españoles pueden prohibirles el comerciar con ellos» De Indis, Relectio I, 3, 3, (Secunda Propositio), p. 708.

79 José María Desantes-Guanter, «Los mensajes simples en el 'Ius Communicationis' de Francisco de Vitoria», en Persona y Derecho, No 20, (1989): 191-209. Vid., también, del mismo autor, «Caracteres del ius communicationis en Francisco de Vitoria», en Hispania Christiana (Estudios en honor del Prof. Dr. José Orlandis Rovira en su septuagésimo aniversario), (Pamplona: EUNSA,1988), 523-544. El autor sostiene que no ha habido un esfuerzo detenido por estudiar lo que Vitoria entendió como ius communicationis que entiende relacionado con el hoy llamado derecho a la información.

${ }^{80}$ De potestate civili, en la citada edición de Teófilo Urdanoz, Obras de Francisco de Vitoria, Relecciones Teológicas, (Madrid: Biblioteca de Autores Cristianos, 1960).

${ }_{81}$ Vitoria, De Potestate civile, 156.

82 Vitoria, De Potestate civile, 156.

${ }^{83}$ Urdanoz, introducción a Obras de Francisco de Vitoria, Relecciones Teológicas, 116. 
de su ser espiritual: de la necesidad de su desarrollo intelectual, del ejercicio del don de la palabra (...) y de los frutos virtuosos de justicia y amistad que ha de reportar la voluntad» ${ }^{84}$.

Por eso, en la Prior De Indis vitoriana, el ius societatis et communicationis es una misma $\operatorname{cosa}^{85}$, porque una misma cosa son la comunidad y la comunicación: «la sociedad es como si dijéramos una naturalísima comunicación, muy conveniente a la naturaleza» ${ }^{86}$. En consecuencia, la naturalidad de la comunidad lo es también de la comunicación, y viceversa ${ }^{87}$. La comunidad es natural porque es necesaria ${ }^{88}$, ya que «así como el hombre sobrepasa a los animales por la razón, por la sabiduría y por la palabra, así a este eterno inmortal y sabio animal le fueron negadas por la Providencia muchas cosas que fueron atribuidas y concedidas a los restantes animales ${ }^{89}$. El hombre necesita pues a los demás hombres, como ya adelantara el estagirita, y Vitoria precisa que «para subvenir, pues, a estas necesidades fue necesario que los hombres $(\ldots)$ viviesen en sociedad y se ayudasen mutuamente ${ }^{90}$. Y el entendimiento, del que el hombre está dotado natural e individualmente, a diferencia de los animales, «solo con doctrina y experiencia se puede perfeccionar, lo que en la soledad de ningún modo puede conseguirse $\rangle^{91}$.

Siendo así las cosas, la razón humana (el entendimiento, en términos vitorianos) se nutre de mensajes que puede recibir por la palabra (o por escrito), como el dominico burgalés resalta: «la palabra es anuncio del entendimiento y para eso fue dada, como dice Aristóteles, con la cual se eleva al hombre sobre los animales $\rangle^{92}$. Pero la palabra (que articula los mensajes que se transmiten y reciben) sería inútil sin la comunidad: «mas la palabra si estuviera en soledad, la tendría inútilmente; y la misma sabiduría, si se diera sin la palabra, parecería ingrata e insociable, conforme a aquello del Eclesiástico: la sabiduría escondida y el tesoro no visto, ¿qué utilidad reportan?» ${ }^{93}$. Y remata el argumento Vitoria destacando la relación de la palabra con la voluntad humana y la virtud de la justicia: «A su vez, la voluntad, cuyos ornamentos 116.

${ }^{84}$ Urdanoz, introducción a Obras de Francisco de Vitoria, Relecciones Teológicas,

${ }^{85}$ Desantes-Guanter, «Caracteres del ius communicationis en Francisco de Vitoria», 533.

86 «...communitatem ese naturalissimam communicationem naturae convienentissimam», Vitoria De potestate civile, 156.

${ }^{87}$ Vitoria, De potestate civile, 157.

${ }^{88}$ Vitoria, De potestate..., 152.

89 Vitoria, De potestate..., 152.

90 Vitoria, De potestate..., 155.

91 Vitoria, De potestate..., 155.

92 Vitoria, De potestate..., 155.

93 Vitoria, De potestate..., 155. 
son la justicia y la amistad, quedaría del todo deforme y defectuosa, alejada del consorcio humano; la justicia, en efecto, no puede ser ejercitada sino entre la multitud, y la amistad, sin la cual no disfrutamos del agua, ni del fuego, ni del sol, como Cicerón dice en muchos lugares, y sin la cual, como Aristóteles enseña, no hay ninguna virtud, perece totalmente sin la comunicación $\rangle^{94}$.

De esta forma adelanta en siglos Vitoria el significado y contenido nuclear del actual derecho a la información, entendido como derecho y deber de comunicar y deber y derechos correlativos a recibir información; todo ello bajo un principio general de libertad (vid., v.gr., art. $19 \mathrm{DUDH}$, citado al inicio) que solo en casos justificados puede legalmente restringirse. Y particularmente, el principio de libertad de navegación por la red y de no inferencia injustificada en la misma por parte de gobiernos o empresas («neutralidad de la red») encajaría perfectamente a nuestro juicio en el esquema vitoriano sobre el contenido y significado del ius communicationis como principio de derecho natural, pues, como subrayó el catedrático de Salamanca, «todas las cosas que no están prohibidas o que no van en perjuicio o contra el derecho de otro son lícitas ${ }^{95}$. Cualquier prohibición ha de estar fundada y no puede ir contra el derecho natural: si así fuera no tendría fuerza de ley. «Si, pues, hubiera alguna ley humana que sin causa alguna prohibiera lo que permite el derecho natural y divino, sería inhumana e irracional, y, por consiguiente, no tendría fuerza de ley» ${ }^{96}$. Es más, no se puede prohibir ningún mensaje salvo que su difusión redunde en daño del que lo prohíbe ${ }^{97}$ [lo que hoy día se puede interpretar sin mucho esfuerzo como un rechazo expreso de todo tipo de censura en la red], ni mucho menos cuando con la prohibición del mensaje se impide la obtención de algún bien ${ }^{98}$, pues en este caso la ley prohibitiva sería inicua y contra caridad. La comunicación es, además de necesaria, deseable como instrumento (...) de amistad y sociedad humanas ${ }^{99}$. Las excepciones pueden llegar, incluso, a evitar lo inconveniente ${ }^{100}$ hoy día, por ejemplo, la delincuencia, o el fraude en la red], guardando siempre la justicia y la moderación para que no se vaya más allá de lo necesario ${ }^{101}$, según la calidad del asunto $^{102}$ y la del receptor ${ }^{103}$ [luego serían justas, por necesarias, excepciones

\footnotetext{
94 Vitoria, De potestate..., 155-156.

95 Vitoria, Prior de Indis, 706.

96 Vitoria, Prior de Indis, 708.

97 Vitoria, Prior de Indis, 709.

98 Vitoria, Prior de Indis, 709.

99 Vitoria, Prior de Indis, 711.

100 Vitoria, Prior de Indis, 718.

101 Vitoria, Prior de Indis, 708.

102 Vitoria, Prior de Indis, 714.

103 Vitoria, Posterior de Indis, 832.
} 
como las que establece el Reglamento UE, para evitar la delincuencia a través de la red, la vulneración de los derechos de autor, o incluso la publicidad abusiva].

Cierto que las referencias que Vitoria hace a españoles e indios pueden generalizarse a todos los hombres, como apunta Desantes-Guanter ${ }^{104}$, de modo que lo sustancial es que todos los hombres tienen derecho a comunicar mensajes ${ }^{105}$, sin que nadie pueda prohibirlo en ningún momento, salvo que la comunicación redundase en daño de alguien o fuese contra su derecho ${ }^{106}$ [principio básico recogido hoy en la Declaración Universal de Derechos Humanos]. En este sentido universalista, los hombres están al menos obligados a escuchar afablemente (y no rechazarlos) a quienes les comunican mensajes ${ }^{107}$, mucho más cuando tales mensajes constituyen la comunicación de bienes ${ }^{108}$ [pensemos simplemente en la difusión de noticias por internet, en el correo electrónico, o en las distintas redes sociales como comunicadores de «bienes»]. Y la presunción de que el mensaje es recto está a favor de quien lo comunica ${ }^{109}$, si bien esto no le excusa de que se demuestre con la claridad del mensaje su corrección ${ }^{110}$ siendo además que la rectitud del mensaje se logra por un conjunto de concausas («de la integridad de las causas»), todas ellas necesarias, de modo que el mal en una sola de ellas hace que el mensaje sea incomunicable ${ }^{111}$ [principios que podrían iluminar el tratamiento de las «fake news» en la red]. Por último, si el receptor no opone obstáculo a la comunicación de los mensajes, no debe por eso el emisor abusar de la facilidad comunicativa que se le ofrece ${ }^{12}$, sino más bien usar del derecho a comunicar con moderación y modestia ${ }^{113}$ [pareciera un argumento pensado a propósito del «spam»o correos no solicitados con fines comerciales o publicitarios, tan fáciles de comunicar a través de internet].

${ }^{104}$ Desantes-Guanter, «Los mensajes simples en el 'Ius Communicationis' de Francisco de Vitoria», 198.

105 Vitoria, Prior de Indis, 709.

106 Vitoria, Prior de Indis, 706.

107 Vitoria, Prior de Indis, 714.

108 Vitoria, Prior de Indis, 721.

109 Vitoria, Posterior de Indis, 834. En este caso Vitoria se refiere expresamente al hecho de que en los casos dudosos prevalece el derecho del poseedor.

${ }_{110}$ Vitoria, Prior de Indis, 711-712.

111 Vitoria, Prior de Indis, 718-719.

112 Vitoria, Prior de Indis, 717. «Si los bárbaros permitieran a los españoles predicar el Evangelio libremente y sin obstáculo, ya reciban la fe, ya no, no es lícito por este capítulo declararles la guerra ni tampoco ocupar sus tierras»».

113 Vitoria, Posterior de Indis, 858. 
No fue objeto de la obra de Vitoria realizar un estudio sistemático del mensaje, y las Relecciones Teológicas se desenvuelven en un lenguaje rigurosamente racional expresado en muchas ocasiones de modo esquemático, por no decir parco («paucissima verba», como el propio Vitoria reconoce en De Potestate Civile, 156) pero la realidad de los sujetos y del objeto del ius communicationis no ha variado desde el siglo XVI hasta la actualidad ${ }^{114}$. Con independencia del habla, de la comunicación verbal, en tiempos de Vitoria la imprenta era una realidad que, en palabras de Puddephatt, «abrió la puerta a la a la producción masiva de información y de opiniones, y su circulación a una escala nunca antes imaginada $\rangle^{115}$ y que en su momento produjo un impacto difícil de evaluar pero quizás comparable, mutatis mutandi, al papel que en la actualidad desempeña internet en la sociedad actual como sostén del derecho a la libertad de expresión.

Por eso resulta a mi juicio interesante comprobar como las bases conceptuales que actualmente fundamentan la defensa del principio de neutralidad en la red ya se encontraban en buena medida recogidas en la obra de Vitoria, más de cuatro siglos antes.

Así, hoy día, por ejemplo, la FCC norteamericana defendía, en lo que afecta al principio de neutralidad en la red, como principios básicos para preservar una red libre y abierta los siguientes ${ }^{116}$ : a) Transparencia sobre los términos y condiciones de gestión de la red por los prestadores de servicios de banda ancha; $b$ ) Prohibición de bloqueo de contenidos, servicios o aplicaciones legales por parte de los proveedores de servicios, banda ancha fijos o móviles; c) No discriminación injustificada en la transmisión de datos legales. Por su parte, la UE y el BEREC, en el marco europeo, han consagrado el principio de neutralidad (y de libertad) en internet, con una serie de limitaciones excepcionales justificadas por el bien común de la sociedad (intervención judicial, cogestión de la red, seguridad o integridad de esta). Asociaciones de derecho internacional, como

114 Desantes-Guanter, «Los mensajes simples...», 195.

115 Puddephatt, «Internet y la libertad de expresión»,17. Sostiene en este lugar igualmente el Director Ejecutivo de Global Partners Digital y estrecho colaborador de UNE$\mathrm{SCO}$, que «Aunque, en retrospectiva, aún hoy es difícil determinar el impacto que tuvo la imprenta (...) se podría sostener que en Europa este invento condujo a la Reforma, al Renacimiento, y también a la Guerra de los Treinta Años, lo que demuestra que todo invento tiene también su lado oscuro».

116 Federal Communications Commision (FCC), 10-201, FCC Open Internet Report and Order, 21 de diciembre de 2010, Disponible en http://hraunfoss.fcc.gov/edocs_public/attachmach/FCC-10-201A1_Rcd.pdf, último acceso 10 de octubre de 2018. Como hemos señalado, estos argumentos han sido válidos hasta la administración Trump y el cambio en la presidencia de la FCC en favor del Sr. Aji, momento en que la política norteamericana respecto del principio de neutralidad ha experimentado un giro de ciento ochenta grados. 
por ejemplo la Organización de Estados Americanos, (OEA) a través de sus Informes anuales de la Relatoría Especial para la Libertad de Expresión defiende que «la neutralidad de la red se desprende del diseño original de internet, el cual facilita el acceso y la difusión de contendidos, aplicaciones y servicios de manera libre y sin distinción alguna. Al mismo tiempo, la inexistencia de barreras desproporcionadas de entrada para ofrecer nuevos servicios y aplicaciones en Internet constituye un claro incentivo para la creatividad, la innovación y la competencia» ${ }^{117}$. Y entre los especialistas, a modo de ejemplo, Andrew Puddephatt, realiza las siguientes recomendaciones para los responsables de políticas de aplicaciones: «a) Los proveedores de banda ancha no realizan una discriminación injustificada del tráfico legal (sujeto a una gestión razonable de la red); b) Cualquiera puede introducir aplicaciones y servicios innovadores, sin necesidad de obtener permiso previo o de abonar tasas; c) Los estándares abiertos y el acceso a, y la disponibilidad de, tecnologías y software abiertos deben estar claramente definidos; d) Los controles y restricciones de seguridad cibernética deben cumplir con los estándares de derechos humanos, ser proporcionales a la naturaleza de las amenazas y buscar la protección de los usuarios, y no sus perjuicios» ${ }^{118}$. Y, por último, y no menos importantes, asociaciones no gubernamentales, activistas y diversos sectores sociales reclaman una gobernanza de internet libre y democrática, basada en principios semejantes a los anteriores. Así, por ejemplo, la Coalición Dinámica de Derechos y Principios de Internet, junto con el grupo de defensa de la libertad de internet Access Now, publicaron un resumen de lo principios básicos de su Carta de Derechos Humanos y Principios para internet ${ }^{119}$ entre ellos están la universalidad e igualdad, la accesibilidad, la libertad de expresión y asociación, la libertad en la red.

Una interpretación actualizada de la obra de Vitoria permite, a nuestro juicio, sostener que el principio de naturalis societatis et communicationis, basado en la idea de la doctrina de los bienes comunes (intangibles) constituye hoy día un argumento sólido en favor de la libertad de comunicación y expresión en internet, $\mathrm{y}$, por tanto, en contra de cualquier limitación injustificada o arbitraria al intercambio de datos o informaciones que en ella se produce. Y lo hace sobre argumentos antropológicos (la comunicabilidad y sociabilidad inherente a las personas) como ya lo hiciera Aristóteles, y

117 La cita es del informe de la Relatoría Especial para la Libertad de Expresión de la OEA del año 2013, p. 501, disponible en www.oas.org/es/cidh/expresion/docs/.../internet/ informe_fe_internet_2013.pdf, última consulta 17 de septiembre de 2017.

118 Puddephatt, «Internet y la libertad de expresión», p. 28.

119 Vid., «10 Internet Rights and Principles», Disponible en http://internetrightsandprinciples.org/node/397, último acceso el 16 de noviembre de 2017. 
fundamentalmente a través del saber razonado común ${ }^{120}$, por lo tanto, evidente y extensible a todos los seres humanos en todos los tiempos y lugares.

\section{CONCLUSIÓN}

Es evidente que en vida de Vitoria nadie podía ni tan siquiera imaginar un fenómeno como el de internet. La imprenta se difundía por el mundo desarrollado y contribuía a la defensa de los derechos de las personas en cuanto miembros de la comunidad internacional que sostenía el dominico español. Otros, en su tiempo, o ni tan siquiera se cuestionaron la existencia de esos posibles derechos, o, habiéndosela cuestionado, la negaron. Entre aquellos derechos, Vitoria prioriza el derecho natural de comunicarse con los demás, con quienes conforman la sociedad natural en que todos estamos insertos. Dicho derecho de comunicarse, por cualquier medio y con independencia del contenido de la comunicación, siempre que no cause daño, no puede limitarse injustificadamente. Ni los reyes o emperadores podrían hacerlo, por tratarse de un principio de derecho natural.

Más de cuatrocientos años después, la Declaración Universal de Derechos del Hombre, consagra un derecho similar en su artículo 19. La eclosión del fenómeno internet, desde finales del pasado siglo, nos ofrece un nuevo instrumento, con una potencialidad antes desconocida, para difundir y comunicar ideas, para recibirlas y para compartirlas con los demás. Pero la naturaleza humana sigue siendo esencialmente igual que en el S. XVI. Determinados intereses pugnan hoy día por limitar la posibilidad de libre comunicación y otros sostienen que la comunicación entre personas, por el medio que sea, no puede ser limitada a priori. No se trata de que internet sea gratis o de que haya que pagar o no por determinados servicios que voluntariamente se quieran contratar, sino de que ningún gobierno, ninguna empresa, ningún particular, pueda arbitrariamente limitar el derecho natural que tenemos las personas para comunicarnos entre nosotros. Para difundir libremente y en igualdad de condiciones nuestras ideas o creencias. Lo contrario supondría reconocer que Tocqueville acertó cuando escribió que «si se instaurara el despotismo entre las naciones democráticas de nuestros tiempos, éste adoptaría una forma diferente, sería más extenso y más suave; degradaría a los hombres sin atormentarlos» ${ }^{121}$.

${ }^{120}$ Francisco Elías de Tejada Spínola, Tratado de Filosofía del Derecho, Tomo I, (Sevilla: Publicaciones de la Universidad de Sevilla, 1974), 22 y ss.

121 Alexis de Tocqueville, La democracia en América (México, D.F.: Fondo de Cultura Económica, 1987), 632. 


\section{BIBLIOGRAFÍA}

AIgRAIN, P., «The individual and the collective in open information communities», disponible en http://opensourde.mit.edu/papaers/aigrain3.pdf

Albert MÁrquez, J.J., «Algunas reflexiones sobre el derecho a la intimidad en la red. Especial referencia al llamado «derecho al olvido»». En Cambios Tecnológicos y Derecho, 29-45, editado por Diego Medina Morales, Córdoba: El Granado Ediciones Digitales, 2015.

AÑaños MeZa, M.C., «La doctrina de los bienes comunes de Francisco de Vitoria», en Persona y Derecho, Vol. 68, (2013): 103-137.

— «El título de 'sociedad y comunicación natural' de Francisco de Vitoria. Tras las huellas de su concepto a la luz de la teoría del Dominio», en Anuario Mexicano de Derecho Internacional, vol. XII, (2010): 525-596.

Aquino, T.. Suma Teológica, II-II, Madrid: BAC, 2011.

Beltrán de Heredia, J., Los manuscritos del maestro Fray Francisco de Vitoria. Estudio crítico e introducción a sus Lecturas y Relecciones. Madrid-Valencia: Tipografía Moderna, 1928.

Benkler, Y., The Wealth of Networks, New Haven: Yale University Press, 2007.

CALIFAnO, B. «Políticas de internet: la neutralidad de la red y los desafíos para su regulación», Revista Eptic Online, Vol. 15, n³, sept-dez, (2013): 19-37. Disponible en http://e-tcs.org/wp-content/uploads/2017/03/Califano-2013-Pol\%C3\%ADticasde-Internet-la-neutralidad-de-la-red-y-los-desaf\%C3\%ADos-para-suregulaci $\% \mathrm{C} 3 \% \mathrm{~B} 3$ n.pdf

CAStañeda SABIdo, A. «Análisis de la literatura teórica sobre neutralidad de red y sugerencias de política», EconoQuantum, Zapopan, v. 6, nº1, (enero 2009): 3157. Disponible en http://www.scielo.org.mx/scielo.php?script=sci arttext\&pid=S1870-22009000200003\&lng=es\&nrm=iso

CAstells, M. La Era de la Información: economía, sociedad y cultura. Vol. I. La sociedad red. Madrid: Alianza Editorial, 2000.

CicERÓn, M.T. Sobre los deberes. Traducción, introducción y notas José Guillén Caballero. Madrid: Alianza Editorial, 2015.

CORDERo FuEnTES, J.A. «Los regímenes árabes contra Internet durante la «primavera árabe»: los casos de Egipto, Libia y Siria», en Seguridad y conflictos: una perspectiva multidisciplinar, coord. por Miguel Requena y Díez de Revenga (Madrid: Instituto Universitario General Gutiérrez Mellado, 2012).

Desantes-Guanter, J.M. «Los mensajes simples en el 'Ius Communicationis' de Francisco de Vitoria», en Persona y Derecho, No 20, (1989): 191-209.

- «Caracteres del ius communicationis en Francisco de Vitoria», en Hispania Christiana (Pamplona: EUNSA, 1988), 523-544.

DANS, E. Todo va a cambiar. (Edición social), Cap. V, Introducción a la red. La neutralidad de la red. 2010. Disponible en https://www.todovaacambiar.com/capitulo-5-introduccion-a-la-red-la-neutralidad-de-la-red

ECONOMIDEs, N. y TÅG, J. «Net Neutrality on the Internet: A Two-Sided Market Analysis», Information Economics and Policy, no 24 (2012): 91-104. 
EsCaÑo, C. «Bienes Comunes del Conocimiento: Una propuesta de desarrollo histórico del procomún digital», Opción, Revista de Ciencias Humanas y Sociales, Año 33, n ${ }^{\circ} 82$ (2017): 239-262.

ESPINOSA, C.A. «La información en la red y el principio de neutralidad tecnológica: la libertad de expresión y la difusión de información administrativa», Revista Derecho del Estado, núm. 22, (junio 2009): 83-128. Disponible en http://www. redalyc.org/articulo.oa? $\mathrm{id}=337630232003$

FAssò, G. Historia de la Filosofía del Derecho, Vol. II 2a ed., traducción de José F. Lorca Navarrete, Madrid, Ediciones Pirámide, 1981.

Federal Communications Commision (FCC). «In the matter of preserving the open internet broadband industry practice», disponible en http://transition.fcc.gov/ Daily Releases/Daily Business/2010/db1223/FCC- 10-201A1.pdf

Figueroa AlcÁntara, H.A. «Los bienes comunes de información en la era digital». En, El Conocimiento y la Información como factores de integración de América Latina, ed., por Estela Morales Campo, 19-43. México, D.F., Instituto de Investigaciones Bibliotecnológicas y de la Información, Colección Seminarios de Investigación, 20, Universidad Autónoma de México, 2012.

— «La importancia de los bienes comunes de información para una sociedad y cultura libres». En Memorias del $7^{\circ}$ Seminario Mexicano de Investigación en Bibliotecología y Documentación, ed. por Jaime Ríos Ortega y César Augusto Ramírez V., 597-611. México: CUIB, 2010.

Hess, C. y Ostrom, E. (Eds.) Understanding Knowledge as a Commons. Cambridge, Massachusetts: The MIT Press, 2007.

JIANG, M. «Authoritarian Deliberation on Chinese Internet», Electronic Journal of Communication, 20, (2010), https://papers.ssrn.com/sol3/papers.cfm?abstract_ $\mathrm{id}=1439354$

Justiniano. Cuerpo de Derecho Civil o sea Digesto, Código, Novelas e Instituta de Justiniano. Madrid: Imprenta de Ramón Vicente, 1872.

Lessig, L. Código y otras leyes del ciberespacio, traducción de José Ernesto Alberola Blázquez. Madrid: Taurus Digital, 2001.

- Future of Ideas: the fate of the commons in a connected world. New York: Random House, 2001. Disponible en http://www.the-future-of-ideas.com/download/

Mackinnon, R. No si nuestro consentimiento. La lucha mundial por la libertad en internet. Traducción de Javier San Julián. Barcelona: Ediciones Deusto, 2012.

MCNAMEE, J. «Europa gana, Internet sigue siendo libre», en El País, edición 31 de agosto de 2016, disponible en https://elpais.com/elpais/2016/08/31/opinion/1472639216_221713.html

MARDSEN, C.T. «Neutralidad de la Red: Historia, regulación y futuro», IDP, Revista de Internet, Derecho y Política, Revista de los Estudios de Derecho y Ciencia Política de la UOC, número 13, febrero (2012): 24-42. Disponible en http://idp. uoc.edu/ojs/index.php/idp/article/view/n13-marsden_esp/n13-marsden_esp

Martínez SugastTi, J.L. «Neutralidad de la Red», disponible en jeuazarru.com/wpcontent/uploads/2014/10/Neutralidad_de_red.pdf 
Medina Morales, D. Introducción a Cambios Tecnológicos y Derecho, 29-45, editado por Diego Medina Morales, vii-ix. Córdoba: El Granado Ediciones Digitales, 2015.

O.E.A. Organización de Estados Americanos, Relatoría Especial para la Libertad de Expresión, Informe de 2013, www.oas.org/es/cidh/expresion/docs/.../internet/informe fe internet_2013.pdf

Palazuelos, M.M. y Herrera, F. «La neutralidad de red. Un debate interesado sobre los derechos de los usuarios», Revista TELOS (Cuadernos de Comunicación e Innovación), Fundación Telefónica, Madrid, nº 82 (marzo 2010): 1-12.

PuddephatT, A. «Internet y la libertad de expresión», Cuadernos de Discusión de comunicación Información, $\mathrm{n}^{\circ}$ 6, disponible en http://unesdoc.unesco.org/ images/0024/002466/246670S.pdf UNESCO, (2016): 1-30.

RAMÍREZ MORÁN, D. «Luces y sombras de la neutralidad en la red». Ieee.es Instituto Español de Análisis Estratégicos, Documento de Análisis 15/2015 (205): 1-13. http:/www.ieee.es/temas/ciberseguridad/2015/DIEEEA15-2015.html

RODRÍGUEZ PRIETO, R. «De la «neutralidad» a la «imparcialidad» en la red. Un análisis crítico de la política de la UE sobre internet y algunas propuestas de mejora», Cuadernos Europeos de Deusto, Núm. 57 (2017): 217-246. Disponible en http:// ced.revistas.deusto.es

RYAN, J. A history of the Internet and the digital future. Chicago: The University of Chicago Press, 2010.

Tocqueville, A de. La democracia en América. México, D.F.: Fondo de Cultura Económica, 1987.

Unión Europea (UE). Reglamento (UE) 2015/2120 del Parlamento Europeo y del Consejo de 25 de noviembre de 2015 por el que se establecen medidas en relación con el acceso a una internet abierta y se modifica la Directiva 2002/22/CE relativa al servicio universal y los derechos de los usuarios en relación con las redes y los servicios de comunicaciones electrónicas, disponible en https://www.boe.es/ doue/2015/310/L00001-00018.pdf

VitOrIA, Relecciones Teológicas, edición de Teófilo Urdanoz, O.P. Madrid: Biblioteca de Autores Cristianos, 1960.

Wu, T. «Network neutrality, broadband discrimination», Journal of Telecomunications and High Tecnology Law, Colorado, v. 1, n 2, (2003): 141-149.

— «The Broadband debate, a user's guide», Journal of Telecomunications and High Tecnology Law, Colorado, v. 3, nº 69 (2003): 69-96.

\section{RECURSOS ELECTRÓNICOS}

https://www.adslzone.net/2017/04/27/estados-unidos-acabara-con-la-neutralidadde-la-red-y-permitira-un-internet-de-dos-velocidades/

https://berec.europa.eu/eng/document_register/subject_matter/berec/public consultations/6075-draft-berec-guidelines-on-implementation-by-national-regulators-european-net-neutrality-rules

http://eur-lex.europa.eu/legal-content/EN/TXT/PDF/?uri=CELEX:32015R2120\&fr $\mathrm{om}=\mathrm{EN}$,

https://blog.cnmc.es/2016/06/06/el-berec-y-la-neutralidad-de-la-red/ 
https://www.elconfidencial.com/tecnologia/2015-02-28/asi-te-habria-afectado-perder-

la-neutralidad-de-la-red 719757/

https://elpais.com/tecnologia/2012/02/10/actualidad/1328873270_653423.html

https://elpais.com/internacional/2017/12/14/estados_unidos/1513217068_301815.html

https://www.cnet.com/news/obama-pledges-net-neutrality-laws-if-elected-president/

https://www.fcc.gov/restoring-internet-freedom

https://www.france24.com/es/20180612-estados-unidos-fin-neutralidad-internet

https://www.elcomercio.com/afull/neutralidaddelared-estadosunidos-internet-tecno-

logia-paraquecaches.html.

https://www.muyinteresante.es/tecnologia/articulo/tim-berners-lee

https://webfoundation.org/2017/03/web-turns-28-letter/

http://hraunfoss.fcc.gov/edocs_public/attachmach/FCC-10-201A1_Rcd.pdf 


\title{
EL PRINCIPIO DE NEUTRALIDAD EN INTERNET. UNA APORTACIÓN A LA LIBERTAD DE COMUNICACIÓN EN INTERNET DESDE EL PENSAMIENTO DE FRANCISCO DE VITORIA
}

\section{The net neutrality principle on the internet. A contribution to the freedom of communication on the internet from the thought of Francisco de Vitoria}

\author{
José J. Albert Márquez \\ Universidad de Córdoba (España) \\ ji1almaj@uco.es
}

http://dx.doi.org/10.18543/ed-66(2)-2018pp71-103

\section{Copyright}

Estudios de Deusto es una revista de acceso abierto, lo que significa que es de libre acceso en su integridad. Se permite su lectura, la búsqueda, descarga, distribución y reutilización legal en cualquier tipo de soporte sólo para fines no comerciales, sin la previa autorización del editor o el autor, siempre que la obra original sea debidamente citada y cualquier cambio en el original esté claramente indicado 